\title{
A NATUREZA IDEOLÓGICA E POLÍTICA DO CONHECIMENTO GEOGRÁFICO: O PAPEL DA PESQUISA E DOS CONCEITOS NA QUESTÃO AGRÁRIA ESPANHOLA E BRASILEIRA
}

\author{
Janaina Francisca de Souza Campos \\ Doutoranda do Programa de Pós-Graduação em Geografia \\ Faculdade de Ciências e Tecnologia - FCT - UNESP \\ Pesquisadora do Núcleo de Estudos, Pesquisas e Projetos de Reforma Agrária - NERA \\ Presidente Prudente, São Paulo, Brasil \\ Correio Eletrônico: janadageo.unesp@yahoo.com.br
}

Recibido: 20 de noviembre de 2011. Devuelto para revisión: 15 de diciembre de 2011. Aceptado: 5 de enero de 2012

\begin{abstract}
RESUMO
O presente artigo centra o debate, de forma suscinta, na relação intrínseca que pesquisa, ideologia e política perfazem junto à produção do conhecimento. Através da perspectiva que envolve a questão agrária espanhola em que as políticas agrárias da União Européia pressionam e influenciam as condições econômicas e sociais da América Latina, elucida-se para a natureza ideológica e política que o conhecimento geográfico apreende. Para apresentar essa questão, recorremos ao emprego da multifuncionalidade e da pluriatividade contida nas políticas agrícolas e pesquisas, entendendo-as enquanto conceitos que abrigam o potencial de (re)orientar e até mesmo legitimar o modelo de desenvolvimento rural brasileiro, naturalizando práticas adotadas pelo capitalismo contemporâneo que rege tanto a União Européia quanto os países que integram a América Latina. Com estas reflexões, espera-se contribuir com pensamento geográfico a partir do diálogo crítico e reflexivo sobre o mito da neutralidade científica, demonstrando que as interpretações sobre o espaço geográfico alinham-se, de alguma maneira, a ideologias e posturas políticas.
\end{abstract}

Palavras chave: Multifuncionalidade, Pluriatividade, Política, Ideologia, Conhecimento geográfico.

\section{RESUMEN}

Este artículo centra en el debate, de manera sucinta, la relación intrínseca que la investigación, la ideología y la política conforman cercana a la producción de conocimiento. A través de la perspectiva que implica la cuestión agraria en español que las políticas agrarias de la Unión Europea presionaron a e influyen en las condiciones económicas y sociales de América Latina, aclara la naturaleza ideológica y política que se apodera de conocimiento geográfico. Para enviar esta pregunta, recurrimos al empleo de multifuncionalidad y pluriactividad contenidas en las políticas agrícolas y de investigación, entenderlos como conceptos que son hogar de las posibilidades de reorientar e incluso legitiman el modelo de desarrollo rural, una prácticas brasileño naturalizado adoptado por el capitalismo contemporáneo que rige la Unión Europea y los países que participan en la América Latina. Con estas consideraciones, es esperado para contribuir con el pensamiento geográfico del diálogo crítico y reflexivo sobre el mito de la neutralidad científica, demostrando que las interpretaciones sobre el espacio geográfico alinean ti mismo, de alguna manera, las ideologías y posturas políticas.

Palabras clave: Multifuncionalidad, Pluriactividad, Política, Ideología, Conocimiento geográfico. 


\begin{abstract}
This article focuses the debate the intrinsic relation that search, ideology and politics make up with the production of the knowledge. Through the perspective that involves the spanish agrarian question where the agrarian policies of the European Union pressure and influence the economic conditions and social of Latin America, it elucidates for the ideological nature and politics that the geographic knowledge learned. To present this question, we appeal to the job of the multifunctionality and the pluriactivity contained in the agricultural policies and research, understanding them while concepts that shelter the potential of (reverse speed) guiding and even though to legitimize the model of brazilian agricultural development, naturalizing practical adopted by the capitalism contemporary who conducts the European Union in such a way how much the countries that integrate Latin America. These thoughts, one expects to contribute with geographic thought from the critical and reflective dialogue on the myth of the scientific neutrality, demonstrating that the interpretations on the geographic space are lined up, in some way, the ideologies and positions politics.
\end{abstract}

Key words: Multifunctionality, Pluriactivity, Politics, Ideology, Geographic Knowledge.

\title{
JUSTIFICANDO ESCOLHAS: NOTAS INTRODUTÓRIAS
}

Como parte dos requisitos do Programa de Pós-Graduação em Geografia, a elaboração desse artigo foi originada a partir de reflexões gestadas no Tópico Especial "Las Políticas Agrorrurales de La Unión Europea y su Presión Econômica y Social sobre los Espacios Rurales Latinoamericanos", ministrada pelo docente visitante do Departamento de Geografia da Universidade de Alicante (Espanha), José Antonio Segrelles Serrano. A temática tratada nesse texto, cujo enfoque respalda-se na importância da produção do conhecimento como instrumento que assume posturas ideológicas e políticas, sempre se apresentou recorrente, entretanto, tal discussão mostra-se ausente do rol de preocupações da maioria dos geógrafos. Afinal, "la geografía, así como la universidad, que es donde se desarrolla la mayor parte de la actividad geográfica, ni son ni actúan como entes aislados, al margen de lãs tendencias generales, sino que reflejan de modo fiel las actuales orientaciones globales de tipo cultural, social, político y econômico" (Segrelles, 2002, p. 16).

É impreterível pensar nessa relação, em que o conhecimento científico, ao lado da Filosofia e do senso comum, faz parte de um sistema ideológico que a humanidade apreende o mundo, e se constitui como forma de compreensão e ação sobre a realidade. Do mesmo modo, "la Geografía y la Universidad no constituyen una excepción a la regla general, pues una y otra no actúan como entes aislados y reflejan las tendencias socio-económicas, culturales y políticas globales" (Segrelles, 2001, p. 12). Assim, influenciados por ideologias, os paradigmas impulsionam o processo de construção do conhecimento e, na Geografia, se materializam de inúmeras maneiras. Mais do que um campo de estudo que interpreta a realidade cujo espaço é a sua categoria de estudo por excelência, a Geografia vive num contínuo processo de debate paradigmático.

Este debate do domínio científico, situado no âmbito da disputa de pensamento, marcou o embate entre positivistas, neopositivistas, historicistas, marxistas e fenomenológicos e é mergulhado de preferências, interpretações, valores e crenças. Por isso, destacamos a necessidade de compreender o estudo do espaço geográfico de acordo com o sentido gramsciano, em que a ideologia é concebida como visão de mundo, força histórica e dimensão política, produzida e consumida socialmente. A ideologia é entendida como elemento recorrente e intrínseco da produção do conhecimento que engendra a trajetória da Ciência Geográfica e que permanece, até os dias atuais, selecionando e direcionando a prática científica de acordo com as ideologias e posturas políticas adotadas. 
Para iniciar essa discussão, os conceitos de pluralidade e multifuncionalidade são enfocados, analisando-se, num primeiro momento, a falácia do conceito de multifuncionalidade rural e a sua repercussão na União Européia e América Latina. Posteriormente, segue-se estudando a inserção dos dois conceitos para a compreensão do campo brasileiro e, finalmente, antecedendo as considerações finais, analisa-se como a pluriatividade é concebida por um grupo de pesquisadores que corroboram com essa temática, argumentando para a necessidade de debater o papel que toda a forma de organização do conhecimento rebate junto a sociedade.

\section{A FALÁCIA DO CONCEITO DE MULTIFUNCIONALIDADE RURAL E A SUA REPERCUSSÃO NA UNIÃO EUROPÉIA E NA AMÉRICA LATINA}

De acordo com Segrelles Serrano (2007), o conceito de multifuncionalidade foi forjado no bojo das políticas neoliberais. Com sua gênese ligada a Conferência das Nações Unidas sobre Meio Ambiente e Desenvolvimento, realizado no início da década de 1990 no Rio de Janeiro, o conceito extrapolou a dimensão proporcionada pelo encontro, sendo, a partir de então, utilizado por organismos internacionais, como a FAO e a OCDE. Da mesma forma, as diretrizes que balisaram a Agenda 2000 bem como as políticas públicas, também passaram a conceber em seus documentos o conceito, como é o caso da Política Agrícola Comum (PAC) que, em 1992, fez da multifuncionalidade uma dimensão necessária ao desenvolvimento da agricultura na União Européia.

Segrelles Serrano (2007) apud Massot (2005) versa que a multifuncionalidade faz parte de uma ideologia difundida pela Organização Mundial do Comércio (OMC). Ao contrário do discurso propagado, velado pela preocupação e defesa de uma agricultura sustentável para o desenvolvimento econômico e social, a PAC segue a mesma tendência ideológica ditada pela OMC, mantendo políticas protecionistas que, dada a relação inerente do capitalismo contemporâneo, preocupa-se com a acumulação de capital e na legitimação dos interesses de organismos comerciais internacionais. Assim, a multifuncionalidade nasce ancorada sobre a égide do modo capitalista de produção, sustentado, sobretudo, pela falácia do discurso do desenvolvimento sustentável e do aproveitamento do potencial que o campo apresenta.

No que tange ao espaço agrário espanhol, a Agenda 2000 vem transformando profundamente a paisagem do país, substituindo a comercialização e a produção familiar agrícola pelo financiamento de programas que fomentam, principalmente, a multifuncionalidade dos espaços rurais a partir da concessão de grandiosos recursos ao setor hoteleiro, aos equipamentos voltados ao lazer e entretenimento, a recuperação do patrimônio cultural, paisagístico e arquitetônico. Neste sentido, percebe-se que esta política selecionou e direcionou países a desempenhar papéis terciários, de modo que o turismo rural recebeu demasiada atenção, elegendo áreas especializadas para o desenvolvimento da atividade turística e para o cultivo da monocultura (Segrelles, 2007, apud Martín, 1996).

Assim como na Europa, o fomento a agricultura multifuncional vem tendo seus rebatimentos na América Latina como proposta de desenvolvimento, com destaque para a pluriatividade, multifuncionalidade, maior interação entre agricultura, indústria e tecnologia e o desenvolvimento rural sustentável. Igualmente ao que acontece na Espanha, as políticas neoliberais que impactam o Brasil não privilegiam a agricultura familiar já que não dispõem de recursos suficientes para a produção e comercialização agrícola, soberania alimentar e eliminação da pobreza. As políticas são direcionadas ao estímulo ao agronegócio e a manutenção da desigual distribuição da estrutura fundiária da maior parte dos países latino-americanos (Segrelles, 2007).

Tanto a América Latina como a Europa são fortemente prejudicadas por políticas que entendem a multifuncionalidade como única alternativa para a resolução das problemáticas relacionadas ao campo. De acordo com o mesmo autor: 
Sin embargo, esta deseable multifuncionalidad agrorrural puede convertirse en un mito inalcanzable si no se solucionan antes los verdaderos problemas que obstaculizan el desarrollo positivo del campo latinoamericano: las estructuras agrarias tradicionales y los seculares desequilibrios, injusticias, desigualdad y pobreza que aún caracterizan a estos espacios no urbanos. Tampoco es una solución la imitación irreflexiva del modelo europeo que cristaliza en la reforma de la PAC y la Agenda 2000, ya que aparte de que estas políticas también son discriminatorias y crean exclusiones comunitarias e internacionales, los países latinoamericanos ofrecen una idiosincrasia particular y tienen sus propias condiciones y necesidades (Segrelles, 2007, p. $10)$.

Fica claro que o conceito despreza os reais problemas que afligem o campo, uma vez que a luta pela terra não faz parte do rol de preocupações que regem o atual modelo de produção e é condição estrutural e fundante para a transformação da estrutura fundiária, principal responsável pela pobreza (Segrelles, 2007). Se baseado na atividade agrícola, a multifuncionalidade pode converter-se como alternativa à complementação das famílias camponesas, aproveitando-se, por exemplo, o turismo rural, a cultura local e a comercialização da produção, mas nunca substituindo ou excluindo a natureza e identidade do camponês que, por sua vez, respalda-se na produção de alimentos como modo de reprodução econômico e social.

\section{A INSERÇÃO DOS CONCEITOS DE MULTIFUNCIONALIDADE E PLURIATIVIDADE PARA A COMPREENSÃO DO CAMPO BRASILEIRO}

Os estudos sobre a dita nova ruralidade do campo brasileiro foram pautados, sobretudo, nos conceitos de pluriatividade e multifuncionalidade, pois além dos impactos que as políticas agrícolas dos países europeus trazem aos países periféricos, o conhecimento científico como colocado inicialmente, é entendido como uma tomada de postura política que consagra políticas, práticas e ações em território nacional.

A guisa de esclarecimentos sobre a pluriatividade e a multifuncionalidade, Anjos e Caldas afirmam que a última faz parte de uma formação discursiva articulada diretamente à noção de pluriatividade:

O que aqui se busca alertar é para o fato de que, em nosso país, as aludidas noções foram introduzidas por força da atuação de acadêmicos para dar conta de processos até então desconhecidos ou negligenciados (a pluriatividade), bem como para oferecer concepções inspiradoras (a multifuncionalidade) que qualifiquem o processo de intervenção estatal na agricultura e no mundo rural (Anjos e Caldas, 2009, pp. 25-26).

Como demonstrado pelos referidos autores, historicamente, é o conceito de pluriatividade que abre espaço no plano acadêmico e, neste ponto, no Brasil, a década de 1990 é considerada um período importante que marca esse debate. Um dos pioneiros na difusão desse conceito são os sociólogos Flávio Sacco dos Anjos e Sérgio Schneider. Este último define a pluriatividade:

A pluriatividade permite reconceituar a propriedade como uma unidade de produção e reprodução, não exclusivamente baseada em atividades agrícolas. As propriedades pluriativas são unidades que alocam trabalho em diferentes atividades, além da agricultura familiar [...] (Schneider, 1999, p. 367). 
Entendido como um fenômeno em que os integrantes que compõem a unidade familiar vendem a sua força de trabalho para a execução de atividades não-agrícolas -turismo rural, agroturismo, artesanato - o autor compreende a pluriatividade como agente que possibilita às famílias um significativo aumento dos padrões de vida, na qual a diversificação e complementação da renda familiar são consideradas estratégias de sobrevivência (Schneider, 1999).

Entretanto, é somente com o Projeto Rurbano que efetivamente o conceito ganha repercussão nacional no meio acadêmico (Anjos e Caldas, 2009). No referido projeto, Graziano da Silva e Del Grossi (1999) argumentam a existência de uma nova dinâmica no campo brasileiro iniciado a partir da década de 1980, denominado de "Novo Rural":

[...] no interior das famílias rurais, observa-se uma nova conformação do meio rural brasileiro, a exemplo do que já ocorre há tempos nos países desenvolvidos. Esse "Novo Rural" como vem o temos denominado, pode ser também resumido em três grandes grupos de atividades: a) uma agropecuária moderna, baseada em commodities e intimamente ligada às agroindústrias; b) um conjunto de atividades não-agrícolas, ligadas à moradia, ao lazer e a várias atividades industriais e de prestação de serviços; c) um conjunto de "novas" atividades agropecuárias, localizadas em nichos especiais de mercados (Graziano da Silva e Del Grossi,1999, p. 170).

Para esses estudiosos, a industrialização da agricultura foi responsável pela urbanização do meio rural e a conseqüente diminuição do preço dos produtos comercializados pela agricultura familiar. Isso fez da atividade rural não-agrícola, da agricultura em tempo parcial (part-time) ou pluriatividade (combinação de atividades agrícolas com não-agrícolas por um ou vários membros da família), saídas rentáveis para esta parcela da sociedade, cabendo ao camponês se adequar a lógica de mercado. Dentre elas, os autores destacam o turismo rural como alternativa para a diminuição da pobreza no campo (Campanhola e Graziano da Silva, 2000). Com isso, para esses estudiosos, além de atividades realizadas no interior da propriedade, outras também passaram a ganhar alcance, - pesque-pague, hotel-fazenda, agroturismo, etc. - o que permitiu um representativo desenvolvimento deste ramo (Graziano da Silva, 2007).

Aliado a dimensão política e ideológica de desenvolvimento econômico e social que as políticas européias apreendem, este tipo de visão faz parte do conhecimento geográfico produzido no interior das universidades brasileiras, na medida em que linhas de pesquisa se dedicam a compreensão da pluriatividade. Neste sentido, o Grupo de Estudos Dinâmica Regional e Agropecuária (GEDRA) entende a pluriatividade como estratégia que viabiliza a reprodução social e econômica da agricultura familiar.

O debate sobre as distintas interpretações sobre o campo brasileiro qualifica o pensamento geográfico. Os grupos de pesquisa são concebidos como espaços importantes de difusão do conhecimento, nos quais são construídas pesquisas que trazem distintas interpretações sobre o espaço geográfico, imbuídas de ideologias e de posturas políticas e cujo potencial pode repercutir no modelo de desenvolvimento rural brasileiro, naturalizando práticas e ações. À respeito, Segrelles Serrano corrobora:

[...] pero se olvida con demasiada frecuencia que la ciencia no es neutral y que toda pretensión de carecer de ideología es necesariamente una postura ideológica. Por si esto fuera poco, tanto la enseñanza como la investigación tienen lugar en un marco socio-político y expresan y transmiten, por lo tanto, significados políticos y sociales (Segrelles, 2001, p. 9). 
Por isso, ao contrário da depreciação e desqualificação, é o reconhecimento das distintas formas de pensar, aqui representada pelo GEDRA, que o processo de construção do conhecimento deve ser encarado, analisando, dialogando e, sobretudo, reconhecendo, com coerência e alteridade, as divergências que o conhecimento geográfico pode e deve abrigar quando entendido o poder que os conceitos possuem.

\section{A PLURIATIVIDADE COMO ESTRATÉGIA DE REPRODUÇÃO SOCIAL E ECONÔMICA ADOTADA PELA AGRICULTURA FAMILIAR - UMA LEITURA DO GEDRA}

Tendo como referência muitos dos estudiosos citados anteriormente, as pesquisas desenvolvidas pelo GEDRA compreendem a atividade pluriativa como estratégia de reprodução socioeconômica familiar rural. Para que isso seja melhor compreendido, alguns trabalhos desenvolvidos a nível de pósgraduação foram selecionados e é a partir deles que o debate é orientado.

Moreira e Hespanhol (2004) realizam estudos na compreensão da estrutura produtiva do bairro Aeroporto, no município de Presidente Prudente (SP), cuja localização encontra-se em uma área de transição entre a área urbana e rural. Suas conclusões constatam para o aumento expressivo da diversidade produtiva e econômica do bairro, com a presença de atividades agrícolas e não-agrícolas, ou seja, marcada pela pluriatividade.

Em outro estudo de recorte espacial mais abrangente, Moreira e Hespanhol (2005) propõem entender a relação campo/cidade nos bairros rurais do mesmo município, circunscrita na visão de valorização das atividades essencialmente não-agrícolas que busquem o desenvolvimento rural. Da mesma forma que o trabalho anterior, as pesquisadoras apostam no pluriativismo como estratégia de distanciamento da abordagem dualista para tornar mais íntima as relações entre campo e cidade.

Noronha (2008) apreende a dinâmica pluriativa como estratégia de reprodução de dois bairros do município de Jundiaí (SP). Apoiado em Schneider, de acordo com o autor, o conceito de pluriatividade é importante aos estudos rurais, uma vez que favorece a permanência das famílias no campo:

A partir das contribuições de Schneider (2001), pode-se afirmar que o fenômeno da pluriatividade pode ser compreendido nos dois recortes territoriais de estudo a partir da emergência de um conjunto de atividades, o que revela seu caráter econômico e social com vistas à reprodução social e econômica das famílias no campo. Um ponto de partida é a decadência da agricultura tradicional. Entretanto, salienta-se que esse aspecto, analisado de maneira isolada, não permite caracterizar a complexidade da pluriatividade no âmbito da produção agrícola familiar (Noronha, 2008, p. 226).

Direcionando os estudos para essa mesma temática, Silva (2008) investiga as estratégias de reprodução socioeconômica da agricultura familiar em Jacarezinho (PR) como alternativa que viabiliza a reprodução social e de vínculo com a terra. $\mathrm{O}$ trabalho destaca a subalternidade sofrida pelas famílias diante do domínio do agronegócio e o auxílio que as atividades pluriativas (o trabalho acessório, a aposentadoria e o trabalho dos membros da família em diversas atividades na área urbana) representam, já que complementam a renda nos períodos mais difíceis, mas que não garantem o sustento familiar. Ainda, de acordo com a autora, "se, para a agroindústria, a integração é um grande negócio, para o produtor familiar também o é em parte, pois a relação existente é uma alternativa, temporária, devido às reduzidas opções existentes para o produtor no município estudado" (SILVA, 2008, P. 260). 
A pluriatividade é uma realidade e, nesse sentido, cabe reconhecê-la como atividade que possibilita o aumento das opções de renda de inúmeras famílias. Entretanto, corroboramos com Machado e Casalinho (2010), ao considerar que centralizar o papel da pluriatividade relega a reforma agrária um papel secundário, não a desvelando como condição fundante e estrutural para a transformação da sociedade e promoção da equidade social.

A pluriatividade, conforme definida e entendida pela maior parte dos autores acima citados, tem estreita relação com o processo de descentralização da indústria nos espaços agrários. Dessa forma, a tendência do capital é a de se utilizar do trabalho camponês como mão de obra barata com a finalidade de obter maior acumulação através da mais-valia produzida nessas relações. Assim, o estimulo à pluriatividade nos espaços dos assentamentos da reforma agrária ampliaria a tendência do desaparecimento do camponês e a sua imediata transformação em assalariado fabril, mesmo que se mantivesse como morador, o que geraria uma conflitualidade, e, nesse processo, sua desterritorialização (Machado e Casalinho, 2010, pp. 74-75).

Analisando as produções acima explicitadas, a maioria das pesquisas relacionadas à compreensão da pluriatividade, embora apresentem interpretações que evidenciam as relações de exploração e subalternidade do campesinato seladas pelo Estado e dirigidas pelo grande capital, verifica-se que a questão agrária é tratada de maneira conjuntural, sem a perspectiva de transformação dos padrões estruturais, cuja solução respalda-se na integração da organização camponesa ao sistema capitalista, ou seja, na pluriatividade, valorizando as atividades não-agrícolas como elemento que a reproduz. "Não é possível tentar compreender o campo no Brasil, em sua totalidade, sem compreendermos como se deu e como se dá a apropriação da terra. Não é possível pensar o rural negligenciando os movimentos sociais no campo [...]" (Bombardi, 2003, p. 47).

\section{CONSIDERAÇÕES FINAIS}

O intuito deste artigo procurou relacionar, a partir dos conceitos de multifuncionalidade e pluriatividade e a sua contextualização com a questão agrária européia e latino-americana, a dimensão ideológica e política que toda e qualquer forma do conhecimento geográfico abarca. Buscou-se ilustrar o caráter eminentemente estratégico do saber geográfico por intermédio da instituição universitária, com a análise da produção realizada pelo GEDRA.

Mesmo sabendo da gênese e das limitações que o conceito de pluriatividade e multifuncionalidade enseja ao desenvolvimento de uma Geografia Crítica, isto é, que se comprometa com o desvendamento e a transformação da realidade, as pesquisas que encaminham as interpretações sobre o espaço agrário em direção à esta visão, de nenhuma forma, devem ser estigmatizadas e nem relegadas a um possível subterfúgio ou maniqueísmo. Entende-se que os componentes ideológicos que atuam no interior dessa visão é parte intrínseca do pensamento geográfico sobre o campo brasileiro e deve ser amplamente debatido e respeitado e de forma alguma deve ser analisado sob o sentido de inversão da realidade ou de ilusão que comumente a ideologia é encarada. Como parte que integra a sociedade, a atividade científica traduz-se como fenômeno inerente a sociedade, já que acredita-se que a humanidade sempre possuirá, ao longo da sua existência, inúmeros tipos de interpretações sobre a realidade (Ricoeur, 1983). Partindo desse pressuposto, considera-se que a visão explicitada pelo GEDRA, assim como as dos demais dos grupos de pesquisa, devem ser discutidas, de maneira que a diversidade do pensamento seja elemento aceito e reconhecido diante de toda comunidade científica geográfica. 
Por outro lado, não deve-se esquecer de que estes dois conceitos estão passíveis ao interesse do Estado, de empresas e/ou grupos empresariais (SEGRELLES SERRANO, 2001) que, quando apropriados do conhecimento, pode o utilizar para (re)orientar e/ou por ventura legitimar o modelo excludente de desenvolvimento rural e que corrobora com a desigualdade social que aflige Espanha e Brasil.

Assim como uma parcela da comunidade geográfica brasileira que concebe a dialética como método de estudo e que coloca o conhecimento à serviço da toda a sociedade, é necessário que a Geografia espanhola descubra outros caminhos e cunhe conceitos que deixem de favorecer anseios e interesses da classe dominante. Ao invés do debate centrado na multifuncionalidade, na pluriatividade rural, no ecoturismo, e desenvolvimento agrário, é preciso pensar na agroecologia, na soberania alimentar, na reforma agrária, na luta pela terra e no desenvolvimento rural para que a Geografia se converta numa ciência a serviço de uma sociedade mais justa e menos desigual.

\section{REFERÊNCIAS BIBLIOGRÁFICAS}

ANJOS, F. S. Dos e CALDAS, N. V. A propósito do debate sobre pluriatividade e multifuncionalidade na agricultura: o surgimento de uma nova formação discursiva. Revista Theomai, Argentina, n. 20, p. 22-33, 2009.

BOMBARDI, L. M. Geografia Agrária e responsabilidade social da ciência.Terra Livre, São Paulo, v. 2, n. 21, ano 19, p. 41-53, 2003.

CAMPANHOLA, C. e GRAZIANO DA SILVA, J. F. O Novo Rural Brasileiro: Uma Análise Nacional e Regional. Campinas: EMBRAPA/UNICAMP. 2000. (4 volumes).

GRAZIANO DA SILVA, J. F. e DEL GROSSI, M. E. O novo rural brasileiro. 2. ed. rev. Campinas, SP: UNICAMP. IE, 1999. (Coleção Pesquisas, 1).

MACHADO, A. M. B. E CASALINHO, H. D. Crítica à Pluriatividade e suas relações com o campesinato e a reforma agrária. Revista NERA, Ano 13, n. 17, p. 65 - 80. 2010.

MOREIRA, E. V. e HESPANHOL, R. A. M. A estrutura produtiva e econômica do bairro Aeroporto, município de Presidente Prudente-SP. In: Encontro Nacional de Geografia Agrária, 17., 2004, Gramado. Anais eletrônicos. Gramado: UFRGS, 2004. Disponível em CD-Rom.

MOREIRA, E. V. e HESPANHOL, R. A. M. Relação cidade-campo: um estudo dos bairros rurais do município de Presidente Prudente. In: Simpósio Internacional de Geografia Agrária, 2. , 2005, Presidente Prudente. Anais eletrônicos. Presidente Prudente: UNESP, 2005. Disponível em CD-Rom.

NORONHA, E. O. O espaço rural no contexto da urbanização difusa: o estudo da pluriatividade nos Bairros Rurais Roseira e Toca no Município de Jundiaí (SP). 2008. 262f. Dissertação (Mestrado em Geografia). Faculdade de Ciências e Tecnologia. Universidade Estadual Paulista (UNESP).

RICOEUR, P. Interpretação e Ideologias. 2 ed. Rio de Janeiro: Francisco Alves, 1983. 172 p.

SCHNEIDER, S. Agricultura familiar e industrialização: Pluriatividade e descentralização industrial no Rio Grande do Sul. Porto Alegre: Ed. Universidade/UFRGS, 1999, 205p.

SEGRELLES SERRANO, J. A. Hacia una enseñanza comprometida y social de la geografía en la universidad. Terra Livre, São Paulo, v. 17, p. 63-78, 2001. 
SEGRELLES SERRANO, J. A. Luces y sombras de la geografía aplicada. Documents d'Anàlisi Geogràfica, Departament de Geografía, Universitat Autónoma de Barcelona,v. 40, p. 153-172, 2002.

SEGRELLES SERRANO, J. A. El mito de la multifuncionalidad rural en América Latina. Actas Latinoamericanas de Varsovia, Instituto de Estudios Regionales y Globales, Universidad de Varsovia, v. 29, p. 159-177, 2007.

SILVA, D. O. Transformações no espaço rural do Norte Pioneiro Paranaense: Estratégias de resistência elou permanência dos agricultores familiares no município de Jacarezinho / PR. 2008. 283f. Dissertação (Doutorado em Geografia). Faculdade de Ciências e Tecnologia. Universidade Estadual Paulista (UNESP).

(C) Copyright Janaina Francisca de Souza Campos, 2012.

(C) Copyright GeoGraphos. Revista Digital para Estudiantes de Geografía y Ciencias Sociales, 2012.

\section{Ge Graphos}

